\title{
O debate público como fonte constitutiva da individualidade milliana
}

Gustavo Hessmann Dalaqua

\section{Resumo:}

Neste artigo, apresentaremos a defesa da liberdade de expressão empreendida por John Stuart Mill no ensaio Sobre a liberdade. Seguindo sua estrutura original, separaremos nossa apresentação em três partes. Na primeira, veremos que Mill fundamenta sua doutrina política da liberdade de expressão no falibilismo epistemológico. Na segunda, explicaremos por que toda opinião, independente de sua verdade, deve ser ouvida. Na terceira, ressaltaremos que a defesa milliana da liberdade de expressão não se confunde com permissividade irrestrita. Ao longo do trabalho, defenderemos que o debate público é fonte constitutiva da individualidade.

Palavras-chave: John Stuart Mill - liberdade de expressão - falibilismo indivíduo 


\section{Apresentação}

No século XIX, em resposta à emergência de novas instâncias de controle que oprimiam a individualidade, John Stuart Mill publica uma das mais apaixonadas defesas da liberdade, o opúsculo Sobre a liberdade. Nesta obra, o autor afirma que a liberdade humana compreende três esferas distintas, porém entrelaçadas entre si: a liberdade de pensamento, de expressão e de ação. No corrente artigo, por motivos de concisão, abordaremos as duas primeiras, a saber, a liberdade de pensamento e discussão. Mill reputava que o debate público era constitutivo da individualidade e, como pretendemos mostrar, sua defesa da livre discussão vinha com o propósito de proteger as condições por meio das quais a individualidade é capaz de se desenvolver.

\section{Da liberdade de pensamento e discussão: primeiro ato da defesa}

Mill reserva o segundo capítulo de sua obra à liberdade de pensamento e discussão. Para ele, a defesa de ambas ocorre em conjunto porque uma é inseparável da outra; a liberdade de expressão é indispensável para o florescimento do pensamento e da individualidade. A liberdade de pensamento, segundo Mill, diz respeito ao "domínio interno da consciência [...] em seu sentido mais amplo", o que inclui também o "sentimento" do indivíduo (MILL, I952, p. 272). ${ }^{\mathrm{I}}$ Pensamentos e sentimentos, traços constitutivos de qualquer indivíduo, são produtos histórico-sociais influenciáveis pelo debate público e, portanto, passíveis de retração ou expansão. ${ }^{2}$ Com efeito, a grande preocupação por trás da defesa da liberdade de expressão é a individualidade. Expressar sentimentos e opiniões e compartilhá-los com outrem é imprescindível para o desenvolvimento de si (self-development). ${ }^{3}$

O desenvolvimento de si é tema central no pensamento de Mill e fornece uma boa chave de leitura para Sobre a liberdade. A liberdade é com vistas

I Todas as traduções são de nossa autoria.

2 Tal qual Mill, empregarei os termos "indivíduo" (individual), "individualidade" (individuality) e "eu" (self) indiscriminadamente.

3 Aos nossos propósitos, "desenvolvimento de si" é uma tradução mais apropriada para self-development do que "autodesenvolvimento". O prefixo "auto", aponta o dicionário Michaelis, relaciona-se com o termo "átomo". Já que nosso objetivo é desfazer a percepção de que o indivíduo milliano é individualista, não nos seria, pois, apropriado adotar semelhante prefixo. 
ao desenvolvimento da individualidade almejada pelo filósofo. No caso da liberdade de expressão, veremos, o argumento consiste em mostrar, grosso modo, que o conhecimento humano só progride e o intelecto humano só se desenvolve com o debate público. A argumentação empregada na defesa é bipolar. No polo negativo, Mill supõe casos em que não há liberdade de expressão para mostrar o que daí se perde. No positivo, constrói uma epistemologia para provar a importância desta liberdade.

Passemos em revista esses casos. No primeiro, Mill supõe que "toda humanidade, com a exceção de uma pessoa, fosse de uma opinião" (ibidem, p. 274). Nesse caso, acaso seria lícito silenciar a opinião divergente? De acordo com Mill, de modo algum. A crença mais difundida nem sempre é a mais verdadeira e, como o registro histórico de Galileu evidencia, é perfeitamente possível que a crença de todos menos um seja falsa. Aliás, é perfeitamente possível que qualquer crença seja falsa:

Nunca podemos ter certeza de que a opinião que tentamos silenciar é falsa [...]. A opinião que se tenta suprimir por meio de autoridade pode ser verdadeira. Os que a desejam suprimir, é claro, negam sua verdade; mas eles não são infalíveis [...]. Recusar escutar uma opinião por ter certeza de sua falsidade é assumir que a sua certeza equivale à certeza absoluta. O silenciamento de toda discussão é uma pressuposição de infalibilidade (ibidem, p. 275).

Eis o primeiro elemento da epistemologia milliana: a concepção falibilista do conhecimento. Nunca teremos certeza que uma dada crença corresponde à verdade. Todo conhecimento é, em princípio, falível e nada garante que a opinião da maioria seja verdade. Logo, sem debate livre, a sociedade inteira perde a oportunidade de trocar o falso pelo verdadeiro.

Para ser justo, cumpre-se destacar que a certeza inabalável não tem vez somente no campo do conhecimento. $\mathrm{Na}$ religião, certezas absolutas existem e cumprem um papel indispensável; representam o dogma, ponto inquestionável da doutrina religiosa que Mill de modo algum pretende negar. $\mathrm{O}$ que o filósofo nega, não obstante, é sua veracidade. Diferente do que prega a doutrina católica, os dogmata, contesta o autor, não configuram "verdades reveladas por Deus". ${ }^{4}$ O dogma não deve ser assumido como verdade porque "a liberdade completa de contradizer e desaprovar nossa opinião é a condição que nos justifica em assumi-la como verdadeira [...] e de nenhum outro modo pode 
um ser humano ter qualquer garantia racional de estar certo" (MILL, I952, p. 276). A concepção milliana do conhecimento exclui, assim, o dogma do domínio da verdade: o dogma não é falível e não está aberto à discussão - logo, não é verdade.

Assim concebida, a verdade acaba por fazer da liberdade de expressão sua condição sine qua non. O que justifica a verdade de uma opinião é o teste. A epistemologia milliana, dizíamos, é falibilista. Entretanto, não se deve por isso achar que Mill fosse cético ou relativista. Não se trata de dizer que a verdade inexiste, muito menos de conceder que todas as crenças são igualmente verdadeiras. Para o falibilista, muito embora a certeza absoluta seja inalcançável ao conhecimento, a verdade não necessita de, portanto, ser abandonada. Existem crenças mais verdadeiras que outras e nós podemos descobri-las se as testarmos. E de que modo testá-las senão através do debate livre com teses que lhe sejam contrárias? A construção da verdade requer, portanto, alteridade e diversidade de opiniões.

De acordo com Mill, o falibilismo não é admitido pela maioria porque

As pessoas [...] depositam [...] confiança ilimitada na [...] infabilidade do "mundo" em geral. E o mundo, para cada indivíduo, denota aquela parte do globo com a qual ele entra em contato [...]. A fé que se atribui à autoridade coletiva geralmente não vacila quando se percebe que outras épocas e países [...] pensavam, e ainda pensam, o exato oposto (ibidem, p. 275).

Para a maioria, seu conhecimento, porque compartilhado com o "mundo" em geral, é infalível. Porém, na verdade, o mundo não é unívoco. Variadas religiões e países nele coexistem; várias são, por conseguinte, as "maiorias" que o habitam. Ademais, pertencer a esta ou àquela maioria é fruto do acaso. O equívoco do homem comum é sua incapacidade de depreender o falibilismo a partir da constatação da situacionalidade geográfico-histórica do pensamento. Mill reputa que o estudo histórico deve diminuir a pretensão de certeza e universalidade de nossas visões. A infalibilidade da "autoridade coletiva" da maioria deveria se desestabilizar no momento em que percebemos que outros tempos e países pensam de modo diferente.

A tematização da maioria como fonte de opressão da individualidade é constante em Sobre a liberdade. Ao presenciar a emergência da sociedade de massa, no século XIX, Mill observava o nascimento de novos mecanismos de poder, que extrapolavam o esquema jurídico. O propósito de seu opúsculo, Mill adverte no primeiro parágrafo, é analisar os mecanismos pelos quais 
o poder [...] é exercido, pela sociedade, sobre o indivíduo. Raramente se formula esta questão, [...] que não tardará a ser reconhecida como a questão vital do futuro. [...] No estágio do progresso que as porções mais civilizadas da espécie adentraram, esta questão se apresenta sob novas condições e requer uma abordagem diferente (ibidem, p. 267).

Para compreendermos como a liberdade é possível, é mister uma nova abordagem filosófica, que dê conta "desta violência extra-legal [lawless violence]" que "a lei não alcança" (MILL, 2006, p. I77). No lugar do esquema Soberano-Lei da teoria política clássica, propõe-se uma abordagem mais analítica do que teórica, que não ignore a comunicação polimorfa do poder nas relações sociais. Cumpre-se, pois, denunciar que, a partir do século XIX, com o avanço da democracia e derrocada da monarquia, a representação jurídica do poder deixa de ser a mais apropriada. Doravante, o poder é exercido em nome de uma "autoridade coletiva", a maioria, que sem apelar à lei, passa a oprimir a expressão de sentimentos e palavras que lhe são reprováveis.

Seja como for, talvez fosse possível, reconhece Mill, contestar que, quando pretende silenciar os que a não se conformam, a maioria não pressupõe a infalibilidade de sua opinião. Antes, o que a leva a suprimir a expressão da minoria é a convicção de que suas opiniões e ideias são falsas. Neste caso, a objeção poderia ser assim formulada:

Não há certeza absoluta, porém existe garantia suficiente para os propósitos da vida humana. Podemos, e devemos, para a orientação de nossa conduta, julgar nossa opinião verdadeira; não é senão isto o que fazemos quando proibimos homens malvados de perverter a sociedade com a propagação de opiniões que julgamos falsas e perniciosas (MILL, I952, p. 276).

Todavia, ainda que admita o falibilismo e substitua "certeza absoluta" por "garantia suficiente", o objetor falha em perceber a relação que existe entre a doutrina epistemológica do falibilismo e a doutrina política da liberdade de expressão. De acordo com o falibilismo, a mera "garantia suficiente" da verdade também requer um exame atento das proposições contrárias. $\mathrm{O}$ corolário do falibilismo é, mais uma vez, transformar a liberdade de expressão em condição sine qua non da verdade: a verdade só se justifica contanto se esteja seguro de que "nenhum argumento disponível ou evidência relevante foi ignorado" (SKORUPSKI, I99I, p. 378). Eis, enfim, a resposta de Mill à questão central da epistemologia: 
[A] única maneira do ser humano alcançar um conhecimento completo sobre um assunto é através da escuta do que as pessoas das mais variadas opiniões têm a dizer e através do estudo de todos os modos por meios dos quais o assunto se manifesta [...]. Nenhum homem jamais adquiriu sabedoria de outro modo que não este [...]. O hábito arraigado de corrigir e completar uma opinião através da colação com a opinião de outrem [...] é sua única fundação (MILL, I952, p. 276, grifo nosso).

É pela colisão com opiniões diferentes que o intelecto humano adquire conhecimento. O fundamento do conhecimento é, pois, a liberdade de expressão. Longe de transcendental, o fundamento é imanente à conversação dos homens e se ancora no debate público. Conhecimento e verdade não provêm da Revelação nem da Razão pura. São produtos histórico-sociais que se estabelecem no diálogo e que se sustentam à medida que o intercâmbio de informações se mantém aberto.

A verdade milliana é plural e multifacetada (cf. SKORUPSKI, I99I, p. 382). Ela se deixa mostrar por vários lados e torna-se mais acurada quando mais indivíduos a perscrutam. Eis aí outro liame entre pensamento livre e liberdade de expressão: não é sozinho que se conhece a verdade. Para alcançar a verdade, devemos nos juntar aos outros. O conhecimento do indivíduo é, pois, comunitário.

A filosofia milliana não é atômica. O indivíduo enquanto átomo isolado é uma ficção, um recurso teórico a que Mill não quer recorrer. Este ponto é digno de nota, pois não poucos são os que o ignoram e descrevem o sujeito milliano como átomo isolado, que rivaliza com a comunidade (vide GAIRDNER, 2008, p. IO). Mill valoriza a comunidade e sabe que a identidade humana é dialógica, ou melhor, sabe que o desenvolvimento de cada indivíduo reflete e depende da comunidade (cf. MILL, I952, p. 294).

$\mathrm{Na}$ primeira parte de sua defesa, Mill conclui que quem perde com a ausência de liberdade de expressão não é somente a minoria, mas também a maioria. A justificação do conhecimento aumenta conforme sua extensão: quanto mais fatos conheço, mais verdadeiro e justificado é meu conhecimento. Logo, se a extensão deste domínio me é propositadamente constrangida, meu "desenvolvimento mental é paralisado" (ibidem, p. 282). Adiante, veremos que isto é uma constante. Sem liberdade não há desenvolvimento humano, de modo que toda a sociedade sai perdendo com a ausência de liberdade de expressão. 


\section{Da liberdade de pensamento e discussão: segundo ato}

Passemos agora à segunda divisão do argumento. Ao invés de supormos que qualquer uma das opiniões recebidas seja falsa, suponhamo-las verdadeiras e examinemos o valor que elas provavelmente têm, enquanto objeto de crença, quando a sua verdade não é aberta e livremente investigada (ibidem, p. 283).

Na primeira parte da defesa, estudamos a situação em que todos menos um estavam errados. Imaginemos agora o reverso. Suponha-se que noventa e nove por cento creem em $\mathrm{X}$ e que $\mathrm{X}$ é verdadeiro. A despeito de sua assustadora popularidade, há um homem que não acredita em X. Deveríamos, neste caso, dar ouvidos a este indivíduo? Se $\mathrm{X}$ já é a verdade, por que não silenciá-lo?

Para Mill, mesmo quando estamos na posse da verdade, a objeção contrária merece ser ouvida. A pessoa que discorda de mim me faz um favor, independentemente de sua objeção estar certa ou errada, pois me presenteia com a oportunidade de testar minha crença. E o teste, lemos alhures, é a única garantia que tenho de que minha crença não é falsa. Se o confronto com a objeção comprovou que minha crença $X$ estava certa e que a não $X$ era errada, isto não significa que o procedimento tenha sido debalde. Testar nunca é perda de tempo porque é com ele que se aumenta a força de minha convicção. Quanto mais testo $X$, mais seguro $X$ se torna: se repetidamente submeto $X$ a testes, e repetidamente $\mathrm{X}$ se prova verdadeiro, então maior é a probabilidade de que $\mathrm{X}$ continue a suportar testes futuros.

Suponhamos que haja no mundo um conjunto de dados empíricos consecutivos. Duas teorias foram inventadas a fim de explicar esta conjunção constante, e ambas, cada qual a seu modo, satisfazem este propósito. Qual das duas é digna de maior confiança? Com Mill, a resposta é simples: aquela cuja verdade tenha sido provada mais vezes. Dito de outro modo, é na teoria mais testada que se deve repousar maior confiança.

Estranho notar que este princípio milliano possa conflitar com o princípio de economia. Também denominado de princípio de parcimônia, o princípio de economia afirma que dentre duas teorias igualmente plausíveis, devemos preferir a mais simples. Ocorre que nada impede que a teoria mais testada seja a mais complexa. Aliás, é presumível que a teoria mais complexa, justamente porque envolve um maior número de teses, seja a mais disputável e, portanto, a mais testada. Neste caso, a filosofia de Mill, tomando a maior quantidade de testes como critério de seleção entre as teorias, situar-se-ia contra o princípio de parcimônia. Seja como for, visto que este representaria 
apenas um dentre vários casos nos quais a aplicação do princípio de economia não é bem-sucedida, não nos delonguemos no assunto.

Mill acrescenta outro item na lista de benefícios provenientes da liberdade de expressão:

Mas em qualquer disciplina onde a divergência de opinião for possível, a verdade depende de um balanço a ser encontrado entre dois conjuntos de razões conflitantes. [...] Deve-se mostrar porque a outra teoria não pode ser verdadeira, e até que se mostre isto, jamais entenderemos os fundamentos de nossa crença (ibidem, p. 284).

Além de asseverar a convicção, o teste aumenta a extensão de meu conhecimento de X. Explicando porque não X não é o caso, acabo entendendo melhor porque $\mathrm{X}$ é o caso. Nesse sentido, meu entendimento acerca das bases de minha crença é aprofundado.

Em última instância, o que está em questão é a liberdade de informação: liberar a circulação da informação, tanto as certas quanto as erradas, configura a situação que no jargão econômico chama-se de "ganha-ganha". Quando tudo está aberto à discussão, todos saem ganhando: quem apresenta a tese errada ganha porque se depara com a oportunidade de trocar o falso pelo verdadeiro; quem apresenta e defende a certa, adquire um aprofundamento da compreensão da verdade.

Conhecer crenças diferentes - ou mais amplamente, conhecer o diferente - é, pois, importante. Conhecimento, verdade e desenvolvimento humano emergem de um fundo social plural, sem o qual não se sustentam. Para que o eu se desenvolva e se aperfeiçoe, a presença de um outro é indispensável porque

a diferença de um homem com outro é geralmente a primeira coisa que chama a atenção de cada um deles para a imperfeição do seu próprio tipo, para a superioridade do outro, ou para a possibilidade, mediante a combinação das vantagens de ambos, de produzir algo melhor do que cada um (ibidem, p. 30I).

O indivíduo livre milliano, portanto, não é alguém que meramente "se asila do mundo" (pace ARENDT, I99I, p. 59). A liberdade, o desenvolvimento de si, se dá em concerto com os demais. O desvendamento do eu ocorre no meio da multidão; é pelo e com o outro que me conheço e desenvolvo. A "variedade de situações" é condição sine qua non para o "desenvolvimento humano" (MILL, I952, p. 302). As faculdades intelectuais e morais que fabricam um indivíduo 
"exercem-se apenas quando há escolha" (ibidem, p. 294). Para haver escolha, é preciso diversidade de estilos de vida, uma pluralidade de "experiments of living" (ibidem, p. 293). A existência do pensamento, do intelecto e do conhecimento humanos depende de condições sociais.

Ao testar minha crença com uma tese diferente, adquiro mais convicção, mais conhecimento e - eis um elemento novo - mais verdade. Outra vantagem do teste proporcionado pela discussão livre é a ampliação da verdade. Invalidar a objeção amplifica a verdade na medida em que sua falsidade requer verdade para ser rechaçada.

Além de multifacetada, a verdade milliana é fragmentária. Mill a concebe como que dividida em partes, o que possibilita, por seu turno, uma descontinuidade. Contudo, disto não se segue que o conhecimento não seja cumulativo. Porquanto mesmo que a passagem de um paradigma teórico para outro ocorra mediante uma ruptura (o que, aponta Kuhn, geralmente é o caso), é inegável que a formulação deste depende daquele. Não há criação científica ex nihilo (cf. ibidem, p. 289). Ainda que a transição a um novo paradigma seja, na medida em que não segue qualquer princípio em voga, descontínua a outro antigo, ela, precisamente por não segui-lo, se remete negativamente a ele.

Alguém poderia objetar a Mill que, não obstante as vantagens da liberdade de pensamento e discussão, quiçá fosse melhor não largar a difusão de informação ao completo laissez-faire. "Sem dúvida" - argumentaria o opositor - "concordo que o debate seja necessário ao progresso e que as informações equivocadas são indispensáveis. Mas não julgo que, por conta disso, justifica-se a disponibilização indiscriminada destas últimas a todos. Existem pessoas cujo preparo intelectual é insuficiente para enfrentar a falsidade. A elas, a informação equivocada, além de nenhum ganho acrescentar, possui o inconveniente de poder desviá-las para sempre do caminho da verdade. Nesses casos, o debate livre é mais maléfico que benéfico. Portanto, creio que o mais correto é destinar as informações de falsidade corruptora apenas aos intelectualmente capacitados".

Mill repugna essa atitude porque a considera contraproducente. Ela sabota aquilo mesmo que pretendia defender: o progresso do conhecimento. Ao confinar o desenvolvimento do conhecimento a uma elite, um número considerável de contribuintes é excluído. É possível que um deles se tornasse um grande gênio, um ajudante excepcional na busca pela verdade. Todavia, se excluído das discussões intelectuais, tal gênio se perde. Em segundo lugar, não esqueçamos que o falibilismo também vale para a intelligentsia, igualmente suscetível ao erro. Logo, nada garante que eles não errem na hora de escolher 
quem atende e quem não atende ao critério de ser intelectualmente preparado (isto é, quem pode e quem não pode participar do debate público).

Ademais, o próprio critério de seleção é profundamente problemático. Que requisitos haveriam de ser cumpridos para que um sujeito se classificasse como intelectualmente capaz? E a quem delegar a tarefa de classificar os homens? Esta decisão é ainda mais espinhosa que aquela e, ainda por cima, perigosíssima. Com efeito, é preferível deixar que a informação corra solta do que confiar o futuro do conhecimento a uma classe privilegiada da população porque "qualquer elite [...] irá desenvolver interesses coniventes a sua classe social e doutrinas ideológicas incriticáveis que os sustentem" (SKORUPSKI, I99I, p. 386).

Resumidamente, vimos que testar uma crença é desejável porque gera mais convicção, mais conhecimento e mais verdade. Agora, o último argumento que Mill usa em sua defesa avança a tese de que é pela discussão livre que as crenças ganham significado:

[P]ode-se pensar que isto [sc. a ausência de discussão livre] seja apenas um mal intelectual, e não moral, que não afeta o valor das opiniões [...]. O fato, contudo, é que não apenas os fundamentos da opinião se perdem com a ausência de discussão, como também seu próprio significado (MILL, I952, p. 285).

Com o cerceamento da discussão, o próprio caráter da crença é afetado. De acordo com Mill, a crença vira então uma palavra vazia, uma fórmula a que se apega irrefletidamente. A ausência de um espaço de livre discussão macula o pensamento e estorva o desenvolvimento moral de si. Se não é mais solicitado a se exercitar, o pensamento atrofia. A consciência fica condenada, pois, a um papel eminentemente passivo:

Mas quando a crença se torna um credo hereditário, a ser recebida apenas passiva e não ativamente - quando o espírito não mais é solicitado [...] a exercitar seus poderes vitais com as questões apresentadas pela crença, a tendência é esquecer tudo que há na crença a não ser seus esquemas (ibidem, p. 286).

Se a consciência não é mais convidada a pôr uma dada teoria em questão, a teoria cessa de ser pensada e passa a ser aceita sem mais. Sem dúvida, continua a ser uma crença, porém há uma diferença muito grande, segundo Mill, em acreditar em algo porque você, após ter pensado e inquirido acerca de sua validade, concluiu que ele é o caso, e acreditar simplesmente porque outros lhe mandaram. No primeiro caso, você testou a teoria, ou seja, submeteu-a ao 
método experimental e desenvolveu seu pensamento crítico. Com isso, você a dotou de significado e verdade, duas qualidades que só a experiência é capaz de formar. Conferiu-a, assim, com aquele "respeito sincero que a razão atribui apenas àquilo que se submeteu ao teste do debate livre e aberto" (KANT apud ARENDT, I992, p. 32). No segundo caso, é até possível que o indivíduo creia naquilo que foi compelido a crer, assim como é igualmente possível crer em um dogma sem nunca tê-lo questionado. Porém, de acordo com a epistemologia milliana, semelhante crença não "merece o nome de conhecimento", pois carece tanto de verdade quanto de significado (MILL, I952, p. 288).

Crenças irrefletidas, por não exercitarem o pensamento, não são interiorizadas pelo indivíduo que as recebe. Apenas se sedimentam sobre a consciência, sem transformá-la ou aperfeiçoá-la. É de se supor, portanto, que a sociedade onde os indivíduos são privados de empregar a razão no debate público seja uma sociedade sem pensamento crítico:

Veem-se então os casos, tão frequentes em nossa era a ponto de ser maioria, em que o credo permanece como que fora do espírito, incrustando e o petrificando contra [...] as partes mais elevadas de nossa natureza; exercendo seu poder [...] como uma sentinela que se aloca sob o espírito e o coração, a fim de garantir que permaneçam ocos (ibidem, p. 286).

A fortiori, a ausência de livre discussão implica o extermínio da própria individualidade. É nesse contexto que se insere a afirmação do autor de que na China do século XIX não existiam indivíduos (cf. ibidem, p. 87). A noção de indivíduo, segundo Mill, resguarda dentro de si certa opacidade e oposição em relação ao meio. O Estado que não disponibiliza um espaço de interação onde a livre discussão possa ser conduzida em concerto ameaça a manutenção da individualidade porque não proporciona mecanismos de desenvolvimento para o pensamento crítico. As pessoas que não são instigadas a examinar criticamente os preceitos de sua conduta não são, a rigor, indivíduos. Mill era profundamente avesso à obediência cega porque acreditava que somente com o pensamento crítico o progresso e desenvolvimento humanos eram possíveis.

Não admira, pois, que a censura foi um denominador comum a toda espécie de tirania que até hoje se conheceu. Como afirmava Kant, mantidos na menoridade, os homens são mais facilmente manipuláveis. A impossibilidade de discutir livremente opera como sentinela sob o espírito, que o impede de alçar voo próprio. A incapacidade de fazer uso do próprio entendimento, O que é o esclarecimento? já o dizia, é não só do homem medroso de si como também do governante, que impede a livre discussão (cf. KANT, 20IO, p. 407). 
Mill alertava que a massificação das sociedades europeias punha a individualidade em risco; "no presente, os indivíduos desapareceram na multidão" (MILL, I952, p. 8I). Mutatis mutandis, é no pensando de Adorno que seu alerta ecoará quase um século mais tarde. Segundo este, a sociedade de massa "perfaz-se sempre pela subjugação de alguns por muitos: a opressão da sociedade exibe [...] os traços da opressão exercida por um coletivo. É essa unidade de coletividade e dominação [...] que se sedimenta nas formas de pensamento" (ADORNO, 2005, p. 39). A sedimentação do pensamento, como opressão da sociedade sobre o indivíduo, foi um fenômeno da sociedade de massa cuja crítica aproxima a teoria liberal de Mill com o pensamento frankfurtiano.

\section{Da liberdade de pensamento e discussão: terceiro ato}

Até aqui consideramos apenas duas possibilidades: que a opinião adotada era falsa, e por conseguinte, que a outra era verdade, ou que a opinião adotada era verdade, e que um confronto com a opinião errada era essencial à apreensão clara e ampla compreensão de sua verdade. No entanto, há um caso mais comum que estes dois (MILL, I952, p. 288).

Os dois casos que analisamos até agora não representam, de acordo com Mill, o mais comum. Geralmente, não é o caso que todos menos um estejam certos, tampouco que estejam errados. No mais das vezes, o que acontece é que todos estão um pouco certos: "as doutrinas conflitantes, ao invés de uma ser verdadeira e a outra falsa, partilham a verdade entre elas" (ibidem, p. 288).

Num tal caso, a liberdade de expressão permanece tão imprescindível quanto antes. A manutenção do debate diversificado de opiniões fornece a cada uma "o restante da verdade da qual cada doutrina possui apenas uma parte" (ibidem, p. 288). Tudo se passa, portanto, como se a verdade se encontrasse dividida entre os homens, o que novamente reforça seu caráter fragmentário. A verdade completa então resultaria da confluência das verdades parciais espalhadas nas opiniões individuais. Sendo assim, mais uma vez, o diálogo é condição sine qua non da verdade. Visto que cada opinião em isolado é parcial, um intercâmbio com opiniões diferentes é preciso. Ademais, nada mais natural que nossas opiniões estejam, via de regra, fadadas à parcialidade, visto que a verdade somente nos é acessível a partir de um ângulo circunscrito. 
Tendo explicitado esses três casos, o filósofo conclui a defesa da liberdade de expressão com a estipulação de um limite: as "opiniões perdem sua imunidade quando [...] sua expressão constituiu uma instigação positiva para algum ato danoso" (ibidem, p. 293). Liberdade, portanto, não se confunde com permissividade irrestrita. Desmentindo as críticas com que Williams o ataca, Mill não considera que um debate livre anárquico é garantia da verdade (vide WILLIAMS, 2002, p. 212 e ss). Decerto que para ele a "discussão livre" é condição sine qua non da verdade. Todavia, o que por aqui se designa de discussão livre comporta limites, por mais vagos que sejam. ${ }^{5}$

Quem descobre como fabricar uma bomba misturando sal e óleo de cozinha é passível de ter sua liberdade de expressão constrangida ao querer divulgar sua receita em rede nacional, pois sua expressão instigaria dano à sociedade. O cerceamento da liberdade de expressão é, pois, justificável quando provoca dano à sociedade.

\section{v. Conclusão}

Conclui-se, pois, que a liberdade de expressão é imprescindível para o desenvolvimento científico-humano. A liberdade de expressão é o único meio de justificar e salvaguardar o conhecimento e a individualidade. Desfazendo a noção de que o liberalismo implica a atomização dos homens, Mill postula que o conhecimento e a descoberta da verdade são atividades essencialmente comunitárias. Nesse sentido, defender a liberdade de expressão é preciso porque é a partir dela que a verdade e o eu se desenvolvem. A ausência de liberdade de expressão confisca dos indivíduos não só a verdade como também aquela benção tão cara a cada um de nós: a chance de poder se descobrir, desenvolver e expressar sua individualidade.

5 Eis os vagos limites que Mill estipula para a liberdade de expressão: "free expression of all opinions should be permitted, on condition that the manner be temperate, and do not pass the bounds of fair discussion" (p. 292). Esta vagueza, contudo, é proposital; a fim de delinear um modelo político aplicável a inúmeros contextos sociais, Mill formulou sua doutrina da liberdade em termos largos. No que exatamente consiste uma "fair discussion", e pelo que se define o conturbado conceito de "dano", cumpre à sociedade discutir. De sorte que o que constitui dano a uma sociedade não necessariamente o constituirá noutra; a noção de dano é culturalmente variável. 


\section{Referências bibliográficas}

ADORNO, Theodor; HORKHEIMER, Max. Conceito de Iluminismo. In: Textos escolhidos. São Paulo: Abril Cultural, 2005. (coleção Os Pensadores).

ARENDT, Hannah. Freedom and Politics. In: DAVID, Miller (Ed.). Liberty. Oxford Readings in Politics and Government. New York: Oxford University Press, I99I.

. Lectures on Kant's Political Philosophy. Chicago: University of Chicago, I992.

GAIRDNER, William. Poetry and the Mystique of the Self in John Stuart Mill. Humanitas, Maryland, v. XXI, 2008.

KANT, Immanuel. Resposta à questão: o que é o esclarecimento?. Trad. de Vinicius de Figueiredo. In: MARÇAL, Jairo (Org.). Antologia de textos filosóficos. Paraná: SEED, 2010.

MILL, John Stuart. On Liberty. In: J. S. Mill. Chicago: Enciclopédia Britânica, I952. (coleção Great Books of the Western World, v. 43).

. Collected Works. Indiana: Liberty Fund, 2006, v. XVIII.

SKORUPSKI, John. John Stuart Mill. Nova York: Routledge, I99I. (coleção The Arguments of the Philosophers).

WILLIAMS, Bernard. Truth and Truthfulness. Nova Jersey: Princeton, 2002.

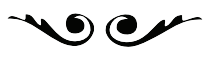

Gustavo Hessmann Dalaqua - Mestrando em Filosofia pela Universidade Federal do Paraná.

gustavodalaqua@yahoo.com.br 